\title{
PRENSA CATÓLICA E IDEOLOGÍA. ALGUNOS EJEMPLOS DE LA SEGUNDA MITAD DEL SIGLO XIX*
}

\author{
Rebeca Viguera Ruiz \\ City University of New York
}

RESUMEN: La sucesión de acontecimientos que tuvieron lugar durante la segunda mitad del siglo XIX en España supusieron una gran influencia en el papel social e ideológico de la Iglesia en el panorama nacional. Tras la aprobación de la libertad de prensa e imprenta, el sufragio universal y la libertad de cultos en el último tercio de la centuria, la institución eclesiástica debió replantearse sus métodos tradicionales de control de las mentalidades. A través del uso de la prensa escrita, y la consiguiente consolidación de lo que dio en Ilamarse periodismo católico, la Iglesia defendió sus intereses y el papel preponderante que el catolicismo debía tener en la sociedad como esencia de la nación española.

Gracias a la conservación y estudio de varios periódicos católicos riojanos, podemos acercarnos un poco más a la naturaleza última de la prensa eclesiástica como adalid de "buena prensa" y abanderada de la lucha antiliberal del ochocientos.

Palabras clave: Prensa, Iglesia, catolicismo, liberalismo y antiliberalismo.

ABSTRACT: The sequence of events that took place during the second half of the nineteenth century in Spain, had a great influence on the social and ideological

\footnotetext{
"Este trabajo se enmarca dentro del Proyecto Nacional de Investigación "Retórica e Historia. Los discursos parlamentarios de Salustiano de Olózaga (1836-1843)", subvencionado por el Ministerio de Ciencia e Innovación. Ref. FFI2008-04419 e investigador principal, el Dr. D. José Antonio Caballero López. Dejamos constancia de nuestro agradecimiento a estas instituciones.
} 
role of the Church on the national scene. Following the adoption of freedom of press and publications, universal suffrage and freedom of worship in the last third of the century, the ecclesiastical institution had to rethink their traditional speeches. Throughout the use of the press, and the resulting consolidation of what became known "Catholic journalism", the Church defended their interests and the role that Catholicism should play in society as the essence of the Spanish nation.

Thanks to the conservation and study of several Catholic newspapers from La Rioja, we can get a bit closer to the real nature of the ecclesiastical press as a leader of a "good press" and the struggle against liberalism.

Keywords: Press, Church, Catholicism, Liberalism and antiliberalism.

Las publicaciones periódicas que surgieron y se difundieron durante el siglo XIX ofrecieron una importante variedad de sustratos ideológicos, muy amplios, en dependencia de los intereses que subyacían a su edición. Éstos podían provenir de posicionamientos políticos o de partido, o bien de tendencias morales o religiosas. En general, esta prensa tuvo un carácter marcadamente político y partidista, con una clara finalidad de difusión y creación de opinión.

De manera general, las fuentes de información de los periódicos provenían fundamentalmente de las ciudades donde se editaban, aunque una mínima parte de ellas pudo proceder de otros lugares y regiones de España. Por este motivo, sobre la base de una necesaria contextualización de la situación general de la prensa en el siglo XIX, en el presente trabajo se intentará dibujar la situación de la prensa local como origen y reflejo último de la realidad nacional. Más concretamente se tratará de analizar la naturaleza ideológica de la prensa local de orientación católica, así como los diques que se pretendieron imponer desde ella a la libertad de expresión.

Con este fin, se tomarán como punto de referencia cuatro publicaciones riojanas que, de un modo más claro durante la segunda mitad de esta centuria, se sometieron ideológicamente a los dictados emanados de las encíclicas pastorales de la época'. Estas fueron El Escudo Católico, La Rioja Católica, La Ciencia Eclesiástica y el Boletín Eclesiástico del Obispado de Calahorra y La Calzada. A través de sus páginas y contenidos puede verse la íntima relación existente en ellas entre el momento histórico que atravesaba la prensa religiosa

1. Para estudiar la prensa local en este contexto que se anuncia debe consultarse el trabajo de Celso Almuiña "Fondos y metodología para el análisis de la prensa local", en VV. AA., Fuentes y métodos de la historia local, Zamora, Instituto de Estudio Zamoramos "Florian de Ocampo", 1991, pp. 389-402. 
del país y la ideología conservadora antiliberal de los periódicos surgidos al amparo de la Iglesia².

A partir del último tercio del siglo XIX se producen varios hechos que preocupan a la Iglesia católica. De manera destacada, junto a la aprobación y creciente aceptación de la Libertad de Prensa e Imprenta o el Sufragio Universal, se había instaurado un nuevo régimen que consagraba la libertad de culto. Estos hechos y la sucesión de acontecimientos a lo largo de la segunda mitad de ese siglo provocaron entre los miembros de la Iglesia el replanteamiento de sus métodos tradicionales de control de mentalidades ${ }^{3}$. Debían acudir a las nuevas vías de captación y formación de opinión que funcionaban en esos momentos. De manera concreta se vieron obligados a hacer uso de la prensa. Por ello se produjo una tendencia generalizada en España, sin que la desconfianza en los medios impresos desapareciera nunca por completo, de instar a los católicos a organizarse en defensa de una Iglesia en peligro.

Es en ese nuevo contexto de necesidad de adaptación a las nuevas realidades socio-políticas e ideológicas cuando surgió el periodismo católico y se produjo la asociación íntima de tres conceptos clave como fueron prensa, educación e ideología $a^{4}$. Tres conceptos que comprenden a su vez a la prensa, la Iglesia y el liberalismo.

\section{Contexto general de libertades. Prensa e Iglesia a lo largo del ochocientos}

Durante la segunda mitad del ochocientos se produjo un proceso de cambios sustanciales para la prensa española, y por consiguiente para la riojana, tras la transformación periodística que tuvo lugar desde finales del XVIII y a lo largo de la primera mitad del XIX. A finales del setecientos la prensa se había especializado y producía publicaciones de carácter informativo, divulgación de

2. Entre los autores que se han dedicado al estudio de la prensa decimonónica local cabe destacar a José Miguel Delgado Idarreta que, de modo concreto, ha profundizado en el estudio del caso riojano. Pueden verse sus trabajos "La prensa local en La Rioja en el siglo XIX: estado de la cuestión", en VV. AA., La prensa española durante el siglo XIX, I Jornadas de especialistas en prensa regional y local, Granada, Instituto de Estudios Almerienses, 1988, pp. 59-65, y "La prensa política del siglo XIX en La Rioja", en Revista de Extremadura, no 10, 1993, pp. 65-70 (número coordinado por el mismo autor).

3. Se ponía de manifiesto el deseo de la Iglesia católica de dominar nuevos instrumentos de control ideológico y de las conciencias. Encontraría una buena vía para ello en el control de los medios de difusión y comunicación eclesiásticos.

4. Puede observarse el análisis de un caso concreto en donde se constata esta realidad en el trabajo de Solange Hibbs-Lissorgues, "La prensa católica catalana de 1868 a 1900. I y II", en Anales de literatura española, ${ }^{\circ}$ 7, 1991, pp. 99-120. La conexión entre los conceptos aludidos queda reflejada en el estudio de $\mathrm{M}^{\mathrm{a}}$ del Pilar García Pinacho, "Prensa, educación y religión en el Sexenio Democrático (1868-1874): la enseñanza católica", en Aportes, n 51, XVIII, 2003, pp. 15-29. 
temas literarios y políticos, periódicos de crítica social o de costumbres, y revistas científicas. Sin embargo, la prensa seguía vinculada al proyecto político de los Borbones y caracterizada por el intento continuado de los legisladores de simplificar la complejidad de las leyes de imprenta. Persistió una legislación sobre prensa e imprenta en base a la censura previa, característica predominante de las legislaciones del Antiguo Régimen ${ }^{5}$. Sobre esta base, pocas innovaciones en las publicaciones impresas y una prensa fundamentalmente local, pobre y mal elaborada, se dio paso al siglo XIX. En el setecientos, el mundo de la prensa fue minoritario y selectivo, pero estaba llamado a erigirse como principal medio de comunicación de masas a lo largo del ochocientos ${ }^{6}$.

En paralelo a la desgastada situación de la prensa durante el siglo XVIII, también se asistió a un largo proceso de escepticismo religioso. Ante los ritmos de constante transformación social, económica y política, la Iglesia Católica no se mostró capaz de adaptar su mensaje de fe. Sin embargo, esta situación comenzó a verse superada cuando aquélla experimentó, en la primera mitad del XIX, una importante evolución y recuperó su presencia y papel en la socie$\operatorname{dad}^{7}$. Se vio involucrada, de un modo más o menos activo, en la Guerra de la Independencia española (1808-1814), sometida después a la persecución por parte de algunos sectores liberales, y finalmente sufrió el descalabro de la Inquisición y se alió con las filas del carlismo.

Dentro de la realidad de la prensa, tras un panorama de rígida censura y ausencia de libertades durante décadas, el año 1810 también constituyó en

5. A lo largo de todo el siglo XVIII la prensa española presentó fases alternativas de desarrollo y retraimiento de manera paralela a los acontecimientos políticos de los Borbones españoles. Así, en las primeras décadas del siglo con Felipe $\mathrm{V}$ en el trono, se vivió un período de pobreza periodística motivada por los numerosos monopolios que impedían la libertad de tirada a los editores. Hacia los años 30 del XVIII se inició una política de expansión cultural que, gracias a una cierta estabilidad económica, facilitó la expansión del periodismo y diferentes corrientes dentro de él como la crítica literaria o política, la divulgación científica o la información nacional e internacional. A mediados de siglo surgieron nuevas medidas de protección a la imprenta en base a la censura previa, y ya en los sesenta se suprimieron las tasas para la mayoría de las publicaciones, se rebajaron los precios de las licencias y se redujeron las tarifas postales. Por estas razones se produjo un importante despegue en el campo de la prensa dando lugar a lo que se ha venido en Ilamar "primera edad de oro del periodismo español". Es de obligada referencia, junto con el volumen La prensa española durante el siglo XIX..., op. cit., la obra de M. Cruz Seoane, Historia del Periodismo en España. 3. El siglo XIX: 1898-1936, Madrid, Alianza, 1996.

6. Un compendio inigualado de estudio local de la prensa decimonónica en estos términos es el que llevó a cabo Celso Almuiña en La Prensa Vallisoletana durante el siglo XIX (1808-1894), Valladolid, Instituto Cultural Simancas, 1977. Posteriormente colaboró en VV. AA., La prensa española durante el siglo XIX..., op. cit., con el artículo "La prensa regional y provincial en la comunidad autónoma de Castilla y León", pp. 13-23.

7. Consultar José Leonardo Ruiz Sánchez, Prensa y propaganda católica (1832-1965), SeviIla, Universidad de Sevilla, 2002. 
España un hito fundamental en el avance hacia la consecución de la ansiada libertad de imprenta. Se entendió entonces como una reforma necesaria y, en ese mismo año, representantes de la prensa periódica como El Conciso o El Semanario Patriótico promovieron una importante "campaña propagandística a favor de la prensa libre ${ }^{\prime \prime}$. A pesar de estos tímidos pero importantísimos avances en cuanto a libertades de imprenta, una vez superada la etapa liberal de las Cortes de Cádiz y la Constitución de 1812, el periodismo español se debilitó de nuevo cuando la reacción de 1814 prohibió lo que entonces se entendía como conquistas liberales.

A la llegada del Trienio renació un cierto espíritu combativo que trajo de nuevo a la luz algunos periódicos y publicaciones de tendencia liberal que en muchos casos se convirtieron en portavoces de los diferentes grupos liberales y constitucionales. Durante este período la hoja diaria y la revista se convirtieron en los medios más adecuados para la tribuna política9 ${ }^{9}$ Una vez finalizado éste, un segundo restablecimiento absolutista en manos de Fernando VII y la reimposición de la censura previa, hicieron nuevamente de la prensa un medio de propaganda controlado por el monarca con la única finalidad de ensalzar los valores de la monarquía y limitar la libertad de expresión. No obstante, la producción periodística española no cesó. Muchos de los liberales que tuvieron que salir al exilio fundaron en Inglaterra, Francia y otros países sus propios periódicos o colaboraron de manera activa en periódicos ya consolidados ${ }^{10}$.

Avanzando en el tiempo hay que observar que durante la era isabelina la Iglesia sufrió un gran impacto en sus estructuras. A lo largo de las regencias, las medidas desamortizadoras, la exclaustración y la situación deplorable en que se encontraban muchas diócesis hizo que la Iglesia se sintiese entonces en un estado de incertidumbre constante. Más adelante, en la década moderada, el Concordato de 1851 favorecía una nueva alianza con el trono y algunos grupos observaron la funcionalidad que la Iglesia podía tener en el nuevo orden socioeconómico. Así, en 1854 las Cortes Constituyentes comenzaron a plantear

8. Francisco Fernández Segado, "La libertad de Imprenta en las Cortes de Cádiz", en Revista de Estudios Políticos, n 124, abril-junio, 2004, p. 30. Puede completarse la referencia con la obra de Emilio La Parra López, La libertad de imprenta en las Cortes de Cádiz, Valencia, Nau Llibres, 1984.

9. Trabajo de Iris M. Zavala, Románticos y socialistas. Prensa española del XIX, Madrid, Siglo XXI, 1972.

10. Caso de cita obligada en este punto fue el de Blanco White, que creó numerosos periódicos y publicaciones en el Londres de aquellos momentos y colaboró activamente con la prensa inglesa. Desde allí reivindicaría el liberalismo español y la necesidad de un cambio sustancial en todos los ámbitos de la realidad española a comienzos del siglo XIX. Vide al respecto el trabajo de José María Martínez de Pisón, José $M^{a}$ Blanco White: la palabra desde un destierro lúcido, Logroño, Perla ediciones, 2009. 
cuestiones como la tolerancia de cultos, la libertad religiosa o la confesionalidad del Estado. Desde el plano educativo, la Iglesia también recuperó y amplió sus competencias gracias a la aprobación de la Ley Moyano de 1857.

Pese a todo, desde mediados del XIX, la persecución y denuncia de los privilegios eclesiásticos por parte del liberalismo fue una constante $y$, tal como el profesor Almuiña reflexionara en su estudio sobre la prensa vallisoletana, probablemente el anticlericalismo fuera una de las características más definitorias de la segunda mitad del siglo XIX en el mundo de la prensa ${ }^{11}$.

Lo cierto es que a lo largo de estas décadas se asistió en España a un progresivo afianzamiento de la libertad en torno a la prensa. Durante todo ese período, la difusión de los intereses políticos que entraban en juego de parte de cada uno de los sectores liberales -moderados y progresistas- cuando ocupaban el poder, era la base ideológica de una prensa marcadamente partidista. En las últimas décadas del siglo, por medio del decreto del 23 de octubre de 1868, Práxedes Mateo-Sagasta legalizó la libertad de prensa desechando toda la censura previa. Y una vez promulgada la ley, hasta 1874, tal libertad alcanzó unas cotas muy elevadas.

En el transcurso de la Restauración fueron restablecidas algunas de las prerrogativas eclesiásticas más importantes. Entre ellas se le devolvieron sus bienes y se anunció la protección del Estado al clero. El régimen canovista pretendió siempre integrar la Iglesia a las fuerzas que sostenían su poder. Por su parte aquélla iba a aprovechar las nuevas libertades de la Constitución de 1876, fundamentalmente la libertad de expresión, para utilizar en su defensa un medio que siempre había condenado, la prensa.

Ya en el último cuarto del XIX, la situación de la prensa sufrió vaivenes significativos. Por el Decreto de 23 de octubre de 1868 promovido por Sagasta, se legalizó la prensa desechando la censura previa. Y en 1883, la Ley de imprenta establecida por el gobierno liberal del mismo D. Práxedes Mateo Sagasta, impulsó las publicaciones periódicas de modo que éstas experimentaron un desarrollo grandioso en el Sexenio Democrático ${ }^{12}$. Así, una vez promulgada la ley, la libertad de prensa experimentó importantes cambios y fluctuaciones que provocaron oscilaciones desde un estricto control hasta una meditada y responsable libertad. Fueron idas y venidas menos acentuadas que en momentos anteriores pero que pusieron en evidencia la enorme influencia del sistema político liberal sobre la regulación periodística.

11. Celso Almuiña en La prensa vallisoletana..., op. cit.

12. Celso Almuiña, La prensa vallisoletana, op. cit., 200. 


\section{Constitución de una prensa católica riojana}

Ante la descrita situación de la Iglesia y la prensa en la segunda mitad del ochocientos, la jerarquía eclesiástica riojana, de modo paralelo al contexto nacional, reaccionó y puso en marcha en la provincia de Logroño una serie de publicaciones destinadas a defender la fe de los cristianos y atacar la impiedad que se agitaba en todos los ámbitos sociales ${ }^{13}$. Sería esa pretensión de salvaguardia de los valores católicos el rasgo definitorio más claro y uno de los recursos más abundantes que pueden encontrarse en el contenido de los periódicos católicos riojanos. Periódicos que, por otro lado, seguían las pautas reguladas por la doctrina eclesiástica y sugeridas desde la dirección de la Iglesia. Por ello, a la defensa de la religión fue siempre unida una crítica mordaz contra el liberalismo como la principal herejía que amenazaba acabar con la fe.

Sin duda una enorme difusión de la prensa en esos momentos atrajo a escritores y autores de todas las ramas políticas. Pero estas publicaciones y las ideas que contenían fueron concebidas por parte del sector religioso como sediciosas, subversivas, obscenas o injuriosas. La Iglesia mantuvo desde un principio una postura opuesta a la Revolución francesa y la libertad de imprenta, pero también a ciertas corrienes literarias que concebía como perniciosas:

\footnotetext{
"Nada más opuesto al espíritu de los sentimientos y a las costumbres de una sociedad monárquica y cristiana que lo que ahora se llama romanticismo, a lo menos en la parte dramática [...]. Esa manía sobre todo de presentar a los ojos de los espectadores los vicios y los delitos, verdaderos o fingidos, de que se han hecho reos algunos ministros de la religión; ese cuidado, en fin, de destruir todas las ideas de orden social y de moralidad, anuncia un plan harto conocido ya por fortuna; y es el de resucitar en la Europa actual el odio contra los reyes, los sacerdotes y las virtudes, y aquella demencia que produjo todos los desastres de la Revolución Francesa"14.
}

Todo el proceso revolucionario se entendió como un complot y una conspiración, cuyos efectos suponían una "peste amenazante"15. Era la mentalidad heredada del espíritu y contenido del Índice de libros prohibidos, "que mandaba estrechar la vigilancia y censura sobre tales publicaciones"

13. En torno a la prensa católica española durante esos momentos vide también José Leonardo Ruiz Sánchez, "La prensa católica en España", en Prensa y propaganda católica..., op. cit. pp. 22-35.

14. La Colmena, publicada en Londres entre 1843 y 1844. Cit. en Iris M. Zavala, Románticos y socialistas..., op. cit., p. 52.

15. Estudiado por Leandro Higueruela del Pino en "El concepto sobre la Francia revolucionaria según el clero español de la época", en Repercusiones de la Revolución francesa en España, Madrid, Universidad Complutense, pp. 555-580. 
porque en ellas se encontraba "el veneno doctrinal" que atentaba contra la fe católica ${ }^{16}$. Son ideas que se iban a prolongar a lo largo de todo el siglo XIX y podrán observarse en las doctrinas trasmitidas por los periódicos de análisis riojanos.

La Iglesia ofreció una postura frontal ante esa imagen de la revolución y el liberalismo como un enemigo al que debe combatirse con todas las armas posibles. Para ello era necesario actuar desde la propia Iglesia, pero también contar con el apoyo del poder civil. Por ese motivo muchos de los autores eclesiásticos que colaboran en los periódicos de la época reflejaron en sus escritos la defensa de los intereses compartidos por el Altar y el Trono. La Iglesia respondía así, mediante la prensa, a las incitaciones de otros grupos políticos que atacaban sus intereses y sus bases.

Sobre todo al final del período isabelino surgen con fuerza las publicaciones periódicas que se autodenominan católicas ${ }^{17}$. Este movimiento de fomento del periodismo católico, que bebió de las fuentes de la creación en París de la Maison de la Bonne Presse en 1873, fue el origen de la creación del concepto "Buena Prensa"18. Todas ellas tuvieron como fin principal la defensa de la Iglesia, del clero y de la doctrina católica. Pero a su vez manifestaron marcados tintes políticos de orientación antiliberal.

\subsection{Prensa eclesiástica en La Rioja: los periódicos riojanos}

A través de la siguiente tabla se han recogido los títulos de todas las publicaciones periódicas editadas en La Rioja durante el siglo XIX que se conservan en la actualidad en la hemeroteca del Instituto de Estudios Riojanos (IER):

16. Ideas sostenidas por Leandro Higueruela del Pino, "Prensa religiosa y eclesiástica oficial", en Juan José Fernández Sanz, Doce calas en la historia de la prensa española especializada, Madrid, Asociación de la Prensa de Guadalajara, 2004, p. 231.

17. Obras generales de consulta pueden ser las clásicas de Solange Hibbs-Lissorges, Prensa y sociedad en España en el siglo XIX, Alicante, Instituto Juan Gil Albert, 1995, VV. AA., Prensa y sociedad en España, 1820-19236, Madrid, Cuadernos para el diálogo, 1975 o VV. AA., Historia de la acción educadora de la Iglesia en España, Madrid, BAC, 1995.

18. Fundada en París por los padres agustinos. Difundía publicaciones periódicas como La Croix, Le Pélerin, Les Contemporains, y a su vez tenía un gran número de suscriptores. Cuando en 1873 Sardá y Salvany redactó su Manual del Apostolado de la Prensa bebió, sin lugar a dudas, de las fuentes de aquélla. Ha de tenerse en cuenta para referir estas cuestiones la obra de M. Cruz Seoane, Historia del periodismo español, I-II, Madrid, Alianza, 1986. 


\begin{tabular}{|c|c|}
\hline Título de la publicación & Lugar y fecha \\
\hline El patriota riojano & Logroño, 1822-1823 \\
\hline Boletín oficial de la Provincia de Logroño & $\begin{array}{l}\text { Logroño, Diputación } \\
\text { Provincial, } 1834 \text { - }\end{array}$ \\
\hline $\begin{array}{l}\text { Boletín oficial de la venta de bienes nacionales de la } \\
\text { Provincia de Logroño }\end{array}$ & $\begin{array}{l}\text { Logroño, Viuda de Brieva, } \\
1843-44\end{array}$ \\
\hline Boletín enciclopédico riojano de anuncios & $\begin{array}{l}\text { Logroño, librería de Ruiz, } \\
1844\end{array}$ \\
\hline La luz riojana: periódico literario y de anuncios & $\begin{array}{l}\text { Logroño, librería de Ruiz, } \\
1844\end{array}$ \\
\hline El zurrón del pobre. Periódico literario y de anuncios & $1851-1852$ \\
\hline Boletín eclesiástico del obispado de Calahorra y La Calzada & Calahorra, obispado, 1853 - \\
\hline $\begin{array}{l}\text { El Escudo Católico. Periódico religioso-moral, científico- } \\
\text { literario }\end{array}$ & $\begin{array}{l}\text { Logroño, librería de Ruiz, } \\
1857\end{array}$ \\
\hline $\begin{array}{l}\text { El Ebro. Periódico de administración, intereses } \\
\text { materiales... }\end{array}$ & Logroño, 1860 \\
\hline El avisador logroñés. Periódico semanal no político & Logroño, 1876 \\
\hline $\begin{array}{l}\text { La crónica riojana. Boletín de noticias, administración, } \\
\text { avisos }\end{array}$ & Logroño, 1880 \\
\hline La Asociación: revista semanal de $1^{\text {a }}$ enseñanza & $\begin{array}{l}\text { Logroño, Maestros de } \\
\quad \text { Logroño, } 1882\end{array}$ \\
\hline La Ciencia Eclesiástica & Calahorra, 1882-1897 \\
\hline Semanario riojano & 1883 \\
\hline Diario de avisos de Logroño & Logroño, s.n., 1885 \\
\hline La ilustración de Logroño & Logroño, 1886 \\
\hline El comercio & Logroño, s.n., 1887 \\
\hline $\begin{array}{l}\text { El postillón de La Rioja. Diario imparcial de noticias, } \\
\text { avisos y anuncios }\end{array}$ & Haro, 1887 \\
\hline La Rioja & $\begin{array}{l}\text { Logroño, Martínez } \\
\text { Zaporta, } 1889 \text { - }\end{array}$ \\
\hline El Calahorrano & Calahorra, 1891 \\
\hline La Rioja Católica & Calahorra, 1891-1893 \\
\hline El Enano & Arnedo, 1894 \\
\hline El Zurriago & 1897 \\
\hline La bandera española. Órgano bisemanal carlista & Logroño, s.n., 1898 \\
\hline La Hoz & $\begin{array}{l}\text { Sto. Domingo de la } \\
\text { Calzada, } 1898\end{array}$ \\
\hline
\end{tabular}

Cuadro no 1. Listado de publicaciones periódicas riojanas del siglo XIX que se conservan actualmente en la Hemeroteca del IER. Fuente: elaboración propia. 
De entre todos estos títulos, las publicaciones que manifestaron una clara orientación católica con tintes de partidismo político antiliberal son El Escudo Católico (Logroño, 1857), La Ciencia Eclesiástica (Calahorra, 1882-1897), La Rioja Católica (Calahorra, 1891-1893), y el Boletín eclesiástico del obispado de Calahorra y La Calzada (Calahorra-Obispado, Logroño, desde 1853). Unas breves notas de cada uno de ellos ayudará a situarlos en su contexto espaciotemporal e ideológico:

\section{a) El Escudo Católico (1857)}

Se conservan quince números de este periódico en una edición que da comienzo el jueves 15 de enero de 1857 y finaliza el 15 de agosto de ese año. Desde el principio de la obra se presenta a los lectores como un "Periódico Religioso-Moral, Científico-Literario" publicado quincenalmente en Logroño ${ }^{19}$. Cada uno de sus números se estructura en diversos apartados temáticos que engloban contenidos ideológicos diferentes bajo un doble objetivo común: la defensa del catolicismo y un ataque directo hacia todo aquello que se opusiera de algún modo a la doctrina cristiana. Aquí el liberalismo ocupará un lugar destacado ${ }^{20}$.

Estas secciones aludidas son cinco: la Sección Primera, de estudios apologéticos; la Sección Segunda, sobre estudios morales o de culto; la Sección Tercera, compuesta de estudios filosóficos, literarios o científicos; la Sección Cuarta, o novela de entretenimiento "Lorenzo o el conscrito"; y la Sección Quinta, que analiza noticias generales bajo el título de "Revista Contemporánea".

Los editores de El Escudo Católico pusieron de manifiesto, desde un principio, su deseo de que los españoles permaneciesen firmes en la religión que habían heredado de sus padres. Ante esa pretensión afirmaban que "el objeto principal en su publicación ha sido defender el catolicismo, que es el único que salvó al mundo pagano de la corrupción general que lo gangrenaba"21. Por tanto el contenido ideológico que subyace a la apariencia externa del periódico, a lo largo de todas y cada una de sus páginas, recoge una clara intención de fondo: la defensa del catolicismo. Se pretendía salvaguardar la fe católica, la enseñanza del cristianismo, la educación en valores de los creyentes, la pureza de la vida religiosa y la omnipotencia

19. Original de El Escudo Católico, Logroño, imprenta de D. Domingo Ruiz; C/ de la Plaza, frente a Portales, n 34, año de 1857.

20. Para completar la visión y análisis de este periódico puede consultarse Rebeca Viguera Ruiz, El Escudo Católico. Edición facsímil, Introducción y notas, Logroño, IER, 2010 y "La prensa católica en el panorama local español a mediados del siglo XIX: el ejemplo de El Escudo Católico", en Berceo, no 159, 2010, pp. 95-121.

21. El Escudo Católico, sábado 31 de enero de 1857, nº 2, p. 37. 
de Dios Padre. Formaba parte de la tendencia nacional por la que, desde el púlpito, la prensa, la tribuna parlamentaria o la imprenta se había puesto en marcha una importante protección de los derechos de la Iglesia orientada a la sacralización de la sociedad ${ }^{22}$.

Así, todos los contenidos que pueden encontrarse en El Escudo Católico se orientan a la presentación de la religión católica como principio básico de la vida y el único camino posible de salvación y de Verdad para el hombre decimonónico. En la medida de sus posibilidades, el periódico y los encargados de su publicación (entre ellos el editor responsable D. Juan Crisóstomo Arroyaga), debían contribuir a ello e inculcar en sus lectores los principios de la religión cristiana con el fin de que no cayesen en los errores comunes de la sociedad del momento y alcanzaran la plenitud que aquélla les confería ${ }^{23}$.

\section{b) La Ciencia Eclesiástica (1882-1897)}

Se presentó a los lectores como una revista mensual puramente científica consagrada al clero ${ }^{24}$. Publicada por primera vez en Calahorra en el año 1882, existen otras dos ediciones consecutivas en 1883-1884 y en 1889. En esta última se especificaría el final de la impresión de esta publicación debido a la escasez de medios y recursos económicos para sacarla adelante. El primero de los tomos se distingue de los demás en que gran parte de sus artículos hablan de las costumbres, instituciones, beneficios, festividades y demás cuestiones de la Iglesia. Es por tanto un libro más bien litúrgico o eclesiástico. El segundo, por cuanto se ocupa de conceptos especulativos podría denominarse filosófico. Mientras que el tercero tiene más relación con las costumbres, la política y el

22. Juan Antonio Inarejos Muñoz, "Sotanas, escaños y sufragios: Práctica política y soportes sociales del neo-catolicismo en las provincias castellano-manchegas (1854-1868)" en Hispania Sacra, vol. 60, n 121, 2008, p. 297. Pueden consultarse también al respecto José María Portillo Valdés, Revolución de Nación. Orígenes de la cultura constitucional en España, 1780-1812, Madrid, CEPC, 2000, o José Ramón Urquijo Gotilla, "La representación desde el antiliberalismo", Ayer, no 61, 2006, pp. 163-187.

23. Pueden verse más referencias en Rebeca Viguera Ruiz, El Escudo Católico..., op. cit., y "La prensa católica en...", op. cit. o también "El miedo a la masonería. Prensa católica riojana antimasónica en el debate público", en José Antonio Ferrer Benimeli (coord.), La Masonería española en época de Sagasta, Zaragoza, Gobierno de Aragón, Departamento de Educación, Cultura y Deportes, 2007, pp. 97-124.

24. En relación con el título y contenidos de este periódico riojano, y dentro de la prensa religiosa de revistas científicas y especializadas, en 1877 el filósofo Ortí y Lara fundó La Ciencia Cristiana, y en los años ochenta apareció La Ciencia Católica, revista religiosa, científica literaria, órgano de las academias de Sto. Tomás de Aquino de Barcelona y Sevilla. Vide más referencias en Leandro Higueruela del Pino, "Prensa religiosa y eclesiástica", op. cit., p. 256. 
orden social, y se caracteriza como moral. En 1897 apareció una nueva tirada del periódico que se correspondía con una segunda edición de la de $1882^{25}$.

Por lo que respecta al carácter de esta revista, puede decirse que desde el primero de sus números los redactores hicieron hincapié en la finalidad y contenidos a los que se aspiraba. Desde las primeras páginas se confiaba a Dios la buenaventura de la publicación y el éxito de la misma entre los lectores. Se ofrecía la misma al Salvador y la Santa Iglesia Católica, para quien los diferentes miembros de la redacción trabajarían y pondrían en marcha sus talentos. En definitiva, se pretendía que "aquellos que lean La Ciencia Eclesiástica se convenzan de que todavía hay abierto un canal por donde puede correr pleno alveo el dulce néctar de la Ciencia" ${ }^{26}$.

Estructuralmente se programaba en base a tres secciones cuyos contenidos respondían a los objetivos iniciales del editor. La primera de ellas Ileva por título Histórica y se conforma de artículos más o menos extensos que versan sobre patrología, filosofía, Sagrada Escritura, teología, moral, escolástica, derecho canónico, disciplina eclesiástica, oratoria sagrada, liturgia, arqueología e historia. En la segunda, Adversaria, se observa la redacción de numerosos conceptos científicos con la misma orientación ideológica pero con la diferencia de ser más breves y escritos con estilo cortado. La tercera sección recibe el nombre de Lemmata y se destinó a exponer ideas sueltas y conceptos breves. Se trataba de "conciliar perfectamente lo grave y serio del artículo de fondo, lo instructivo del suelto que deleita con copia de erudición y lo interesante de la noticia que despierta viva curiosidad allanando de este modo el camino del saber" ${ }^{\prime 2}$.

En definitiva, la intención última de este periódico fue la instrucción; una instrucción que conlleva una férrea defensa de la doctrina Católica y de la moral y disciplina de la Iglesia.

\section{c) La Rioja Católica (1891-1893)}

De nuevo estamos ante una publicación marcadamente católica que introduce el pensamiento de la Iglesia en la España de finales del siglo XIX en relación con la sociedad y las nuevas tendencias que imperaban en ella. Presentado

25. En este caso la diferencia fundamental entre las dos es la estructuración de los contenidos en los diferentes números de las mismas. En 1897 hay menor cantidad de éstos y, por tanto, se acumulan en ellos noticias que en la publicación del año 82 correspondían a números diferentes; tal como se observa en los índices y sumarios de ambos años.

26. Introducción a La Ciencia Eclesiástica, Calahorra, 1882, sin numerar. Se trata de un pliego a modo de circular que muestra las claves sobre las que se articulará el periódico y la intencionalidad del mismo. Se ha respetado la cursiva del original.

27. La Ciencia Eclesiástica, Calahorra, 1882, sin numerar. 
a sus lectores como un "semanario popular religioso" alude a su publicación semanal todos los jueves en Calahorra "con aprobación y censura de la autoridad eclesiástica" ${ }^{\prime 2}$.

Existen dos tomos de este periódico en el IER que responden a las ediciones de 1892 y 1893. El primero de ellos comprende desde su fundación el 1 de octubre de 1891, hasta finales de junio de 1892. Y el segundo engloba la edición del año 93 que, a su vez, se subdivide en dos semestres. Tanto una como otra se llevaron a cabo en Calahorra, en el establecimiento tipográfico de Andrés C. Ciriano.

A nivel de organización interna de la información, la estructura es ligeramente diferente a la de los periódicos anteriores. En este caso hay también algunas páginas dedicadas a temas exclusivamente religiosos donde se ensalza la fe católica por encima de cualquier otro credo. Pero hacen aparición otras secciones más amplias donde, además de figurar noticias religiosas, que nunca desaparecen del todo, aparece información de carácter general. Cada ejemplar se introduce con una sección dedicada a temas diversos como la defensa del periódico frente a algunos opositores (como el caso de La Rioja, diario liberal de Logroño), testimonios cristianos o promulgación de la Fe Católica, seguida por una sección piadosa que se introduce más directamente en la palabra del Evangelio, comentarios de oración y reflexiones sobre la religión. A continuación se observan una serie de Crónicas que ofrecen información acerca de las noticias más relevantes a nivel local, nacional e internacional. Y, por último, una o varias páginas de pasatiempos que incorporan juegos y sentencias de divertimento para los lectores ${ }^{29}$.

Desde una perspectiva ideológica, todos los apartados del periódico mantienen una misma línea de pensamiento. Este hilo conductor se articulaba en base a tres principios fundamentales: un ataque constante al liberalismo, sus promotores y todas las actividades que se vinculen a él; una oposición acentuada frente a todo aquello que vaya en contra de los principios básicos de la Iglesia Católica (liberalismo, comunismo, socialismo, sectarismo...); y un rechazo explícito hacia la política española del momento.

\section{d) Boletín eclesiástico del obispado de Calahorra y La Calzada (1853)}

Este boletín, publicado desde 1853 hasta 1928, tuvo un carácter semanal y, en un segundo momento, quincenal. Se imprimía en Logroño, Imprenta de D.

28. Desde su primer número, La Rioja Católica, Calahorra, tip. de Andrés C. Ciriano, Grande 3, ejemplares desde 1891.

29. Estructura descrita a partir de los originales de esta publicación existentes en el IER. Vide ref. La Rioja Católica, op. cit. 
Domingo Ruiz y su director fue, en su fundación, D. Lucas López ${ }^{30}$. Gozó de una buena acogida entre los católicos riojanos, y de ello da muestra una circular fechada el día 31 de mayo de 1860 en la que el gobernador eclesiástico daba "las mas espresivas gracias á todos y cada uno de los piadosos donantes que hasta ahora han acudido y en lo sucesivo acudan á presentar al augusto Gefe de Nuestra Divina Religión, con el óbolo de su caridad, el testimonio positivo y de respeto y adhesión á su Sagrada Persona y á la Cátedra de San Pedro" ${ }^{\prime 31}$. Junto a este agradecimiento la circular aprovechaba para solicitar una "suscripción voluntaria para atender á las necesidades de Nuestro Santísimo Padre el magnánimo y bondadoso Papa Pio IX"32.

Desde su primer número el propósito de este "proyecto para publicación de un Boletin Eclesiástico del Obispado", era dar noticia de la diócesis "con la prontitud apetecida" ${ }^{\prime \prime 3}$. Estos boletines eclesiásticos surgieron como periódicos oficiales de cada obispado siguiendo el modelo de los boletines oficiales de provincias $^{34}$. El primero de ellos se creó en el Arzobispado de Toledo en agosto de 1846 bajo dirección de Pedro de Alcántara Rodríguez, y el resto de diócesis siguieron su ejemplo a partir de los años cincuenta. Era un buen vehículo de información y se utilizó también para formar al clero diocesano y mejorar sus costumbres de acuerdo a las normativas vigentes de la Iglesia. Fueron en gran medida los defensores y portavoces de los intereses materiales y políticos del clero durante la segunda mitad del XIX.

En el caso concreto de este Boletín riojano, estaba previsto que saliera "a la luz todos los sábados en tamaño, papel é impresión igual a los de este primer número. Contendrá en su parte oficial las disposiciones, que por orden del IIImo. Prelado, de su Provisor y Vicario general, y de la Administración diocesana deban circularse". Junto a ello "se insertarán los anuncios de las vacantes de piezas eclesiásticas, que ocurran en el Obispado y fuera de él, las provisiones de los curatos etc., y cuanto pueda interesar al Clero; menos cuestiones políticas, que bajo ningun concepto se tratarán, ni ventilarán en el Boletín"35.

30. Se toma como referencia en este trabajo el ejemplar del periódico que actualmente se conserva en los fondos de hemeroteca del IER, Boletín eclesiástico del Obispado de Calahorra y La Calzada, Logroño, Imp. de D. Domingo Ruiz, 1853-1928. Se citará a partir de ahora como BEOCLC. El precio de la suscripción de este periódico era de ocho reales cada trimestre franco de porte.

31. Circular en BEOCLC, 31 de mayo de 1860 firmada por el gobernador eclesiástico Dr. D. José Ramón de Yárritu.

32. BEOCLC, 31 de mayo de 1860.

33. BEOCLC, sábado 4 de junio de 1853, p. 1.

34. Fueron creados por Real Orden de 20 de abril de 1833, y sobre ellos escribió ya hace unas décadas Vicente Cárcel Ortí su trabajo "Los boletines oficiales eclesiásticos de España", en Hispania Sacra, 1966, pp. 45-85.

35. Ambas referencias en BEOCLC, sábado 4 de junio de 1853, p. 1. 
Pese a la manifiesta intención de no participar de las ideas políticas del momento, a través de sus páginas y como sucede con el resto de periódicos católicos riojanos, se intuye claramente la postura del clero ante aquéllas y ante el régimen político imperante.

La mayor parte de estos periódicos confesionales tuvieron una vida muy corta como consecuencia de la imposibilidad económica de su mantenimiento. Algo diferente fue el caso del Boletín Eclesiástico del Obispado de Calahorra y La Calzada que, financiado desde la diócesis, prolongaría su impresión durante décadas.

A su vez, este periodismo católico, tanto local o provincial como nacional, tuvo en común en todas sus manifestaciones una adhesión inquebrantable al Papa con un seguimiento total de sus decisiones y magisterio, así como una actitud en exceso defensiva y apologética frente a sus adversarios ${ }^{36}$.

En la línea evolutiva de las cuatro publicaciones se mantuvo la postura defensiva de la Iglesia que podía observarse en el panorama nacional. Frente al nuevo poder liberal del país, el conjunto de la prensa del período puede caracterizarse por un lenguaje altamente combativo. Como afirmara Hibbs-Lissorgues, "la religión y las circunstancias políticas son indisociables" y podrían compararse con "un nuevo campo de batalla"37. Ni siquiera los sectores o publicaciones católicas más moderadas escaparon a los enfrentamientos que conllevaba la aludida defensa eclesiástica.

La Iglesia vio con preocupación la difusión de las libertades de prensa y la atacó desde sus escritos. Desde una prensa eclesiástica, aquélla iba a utilizar la influencia del cuarto poder en su propio beneficio y para sus propios fines ${ }^{38}$.

\section{Adoctrinamiento antiliberal de la prensa eclesiástica durante el siglo XIX}

Como se ha indicado previamente, las circunstancias y ambiente que se vivían a nivel nacional subyacen también en las páginas de la prensa local riojana. La Iglesia, por medio de ésta, sus boletines, catecismos, conferencias, sermones o misiones, se posicionó a favor de la tradición religiosa y la lucha contra el régimen liberal.

Fue una tendencia general en España durante el ochocientos. Pero esta radical incompatibilidad con el liberalismo también fue una premisa difundida y

36. Principios mantenidos por Leandro Higueruela del Pino en "En torno a la bibliografía del Boletín de la Diócesis de Toledo en el siglo XIX", en Hispania Sacra XXXI, 1978, pp. 606-609.

37. Solange Hibbs-Lissorgues, "La prensa católica catalana...", op. cit., p. 107.

38. Por prensa eclesiástica se denominaba la prensa oficial dirigida por la jerarquía eclesiástica pero también toda aquella que tenía como destinatario al clero con un fin informativo y pastoral. 
sostenida desde Roma, especialmente tras el Syllabus de Pío IX (1864). Este mismo pontífice, poco después, trató de reforzar el poder de la Iglesia condenando la libertad de cultos, atacando al liberalismo y mostrando su enfrentamiento con el catolicismo a partir de su encíclica Quanta cura (1865) ${ }^{39}$.

\subsection{Doctrina desde la prensa escrita: las buenas y malas lecturas}

En medio de estas circunstancias y de la proliferación de la prensa escrita durante la segunda mitad del siglo XIX, de la mano de publicaciones liberales se hicieron muy comunes los tratados de religión o doctrina cristiana con el fin de exponer lecciones de teología que pudieran ser entendidas por la mayoría.

Se intentó por todos los medios posibles difundir el gusto por estas buenas lecturas frente a otros textos interpretados como impíos por la Iglesia. Desde esta perspectiva, uno de los órganos que más contribuyó a crear una fuerte red de editoriales y librerías católicas fue el Apostolado de la Prensa a partir de 1871, así como la consiguiente aparición del Boletín Oficial del Apostolado de la Prensa. Desde esta prensa eclesiástica se tomó la iniciativa de condenar en papel a todo lo que sonase a revolucionario o liberal ${ }^{40}$. Considerando su punto de vista, "una de las más grandes calamidades que lamentamos en nuestros tiempos es ese aluvión de libros, folletos, revistas y periódicos dictados por el espíritu del mal, y que sus agentes no se cansan de propagar, valiéndose al efecto de todos los medios que su refinada malicia les sugiere". Tanto era así que, afirmaban, "miles de impresos inmorales e impíos vomita en cada hora del día la prensa irreligiosa y libertina" ${ }^{41}$.

La libertad de prensa trajo consigo la difusión de esos textos. Y el sector eclesiástico nacional se opuso a ellos de una manera clara. Creyeron que "la pasión de leer, ha degenerado hoy en una especie de furor. Hasta las mujeres quieren distinguirse en ella, dejándose ver frecuentemente no ya con un libro devoto en la mano, sino con periódicos, folletos, hojas volantes y otros escritos semejantes" ${ }^{42}$. El mayor problema derivado de todo ello era, según la Iglesia, que:

39. Pueden consultarse trabajos de referencia como los de Carasa Soto, El poder local en Castilla: estudios sobre su ejercicio durante la Restauración (1874-1923), Valladolid, Universidad de Valladolid, 2003, o Elites: Prosopografía contemporánea, Valladolid, Universidad de Valladolid, 1994. También los de Emilio La Parra y Manuel Suárez, El anticlericalismo español contemporáneo, Madrid, Biblioteca Nueva, 1998 o Emilio La Parra y Jesús Pradells, Iglesia, sociedad y estado en España, Francia e Italia (ss. XVIII al XX), Alicante, Instituto de Cultura Juan Gil-Albert, 1991.

40. Y, por consiguiente, condena al socialismo en un momento en que este movimiento parecía imparable y se había convertido en una realidad en la sociedad y la política españolas.

41. La Revista Católica, 16 de diciembre de 1877, pp. 2, 8 y 16.

42. Boletín Eclesiástico del Arzobispado de Toledo, 1869, p. 220. Aludido en Leandro Higueruela del Pino, "Prensa religiosa y eclesiástica", op. cit., p. 244. 
"La repartición de estos libros se hace con frecuencia y de una manera tan insidiosa como el contenido de ellos. Se dan en la calle, se arrojan dentro de las casas, se echan desde los trenes... Sobre todo se procura que lleguen a manos de los jóvenes y a las personas sencillas e incapaces de conocer su malicia y el peligro que encierra su lectura" ${ }^{\prime 3}$.

Frente a esta realidad, durante el último tercio del ochocientos se asistió a un todavía mayor impulso de las publicaciones eclesiásticas. Estas eran entendidas como arma de combate y apostolado frente el extendido discurso anticlerical. Un ejemplo de ello ofrece El Escudo Católico en su edición de 1857 aprovechando cualquier excusa para atacar en sus páginas todo aquello que, de algún modo, guardase relación con el libre pensamiento. En la novela que se desarrolla a lo largo de la cuarta sección Lorenzo o el conscrito, se presenta el caso de uno de los protagonistas, Lorenzo. En oposición a sus vecinos y parientes más conservadores, acostumbraba a leer libros doctos del siglo XVIII y a dejarse llevar por la ideología de la ilustración y los principios liberales.

De otro lado Isabel, protagonista también de la novela "no comprendía cómo podía conciliarse un corazón recto, amable y sincero con un entendimiento ofuscado, y lleno de errores religiosos y morales". Al inicio del relato creía firmemente que el alma de Lorenzo "estaba Ilena de malicia, aborrecía a Jesucristo con furor satánico, y no pensaba sino en abatir y aniquilar, si le fuera posible la grande obra de la redención". Era por entonces partidario de quienes atentaban "contra Jesucristo, su Iglesia, su sacerdocio, su celestial moral; siempre dulces y complacientes en lo exterior, pero llenos de dolor y astucia; siempre con deseos de trastornar todo orden civil y religioso; siempre en acción en los subterráneos de las sociedades secretas; siempre maquinando sediciones y revueltas" ${ }^{\prime 4}$.

En los últimos capítulos dedicados por el periódico a esta novela Lorenzo acabó por convertirse a la fe católica. Y a lo largo de todo su desarrollo se insiste en la necesaria mediación del Espíritu para que el hombre pueda desasirse de todas las ataduras que ciegan su conocimiento y su actitud ${ }^{45}$.

De libros impíos habló también el Boletín Eclesiástico del Obispado de Calahorra y La Calzada a partir de las referencias concretas a la pastoral del Obispo de Barcelona en el año $1853^{46}$, sumándose así a la tendencia general del momento a través del uso de la prensa a favor de sus propios intereses.

43. Boletín Eclesiástico del Arzobispado de Toledo, 1869, p. 222.

44. Todas las expresiones en El Escudo Católico, jueves 15 de enero de 1857, año I, no 1 , p. 23. Se ha adaptado la grafía original.

45. El Escudo Católico, jueves 15 de enero de 1857, año 1, nº 1, p. 23.

46. BEOCLC, 15 de febrero de 1854, II volumen, $n^{\circ} 3$, pp. 22-23. En estas páginas los responsables del periódico afirmaban "Nos dolia y afligia vehemente, empero, el ver aquel vastísimo reino tan benemérito de la iglesia católica y de esta santa sede por infinitos hechos gloriosos y esclarecidos tan agitado en los últimos tiempos por lamentables revoluciones; y de tal modo 


\subsubsection{Lucha activa desde las filas de la Iglesia}

Todo este proceso de auge del periodismo católico frente a los diarios liberales tuvo lugar a lo largo de años de gran auge de librerías y editoriales de tipo religioso. Los textos eclesiásticos debían tener un carácter didáctico y para ello, en muchas ocasiones, se escribían a base de preguntas y respuestas ${ }^{47}$. En estos folletines a modo de diálogos uno o más personajes eran los encargados de adoctrinar, y otro recibía las enseñanzas. Es el caso del ejemplo aludido de la novela Lorenzo o el conscrito trascrita en las páginas de El Escudo Católico.

Para alcanzar estos fines, la Iglesia buscó el apoyo del poder civil. Desde las páginas del Boletín eclesiástico riojano, el clero se manifestaba satisfecho de la orientación católica de la política de Isabel II. Consideraban necesario un acercamiento entre ambos poderes con el fin de "poder restablecer en España las cosas de la Religión y de la iglesia"48. Era obligación de la Iglesia y sus sacerdotes "refrenar y castigar la audacia de los que dedican especialmente sus esfuerzos á pervertir los entendimientos y corromper las costumbres del pueblo fiel, y cuando hayan de alejar y desterrar de su grey la detestable y perniciosísima peste de los malos libros" ${ }^{\prime \prime}$.

Frente a la vida plena que el catolicismo ofrecía, surgían por doquier tendencias que se oponían a él y pretendían extirparlo de la sociedad. Ante esa realidad debía actuar la Iglesia Católica a través de la Ilamada prensa eclesiástica. Según El Escudo Católico era la Providencia de Dios la que permitía al hombre mantener sus virtudes. Aquél es capaz de dominar la naturaleza gracias al don de su inteligencia, pero si se aleja de Dios cae en el pecado y la destrucción. Tan sólo aquellos que eran capaces de ser modestos, de seguir los precep-

que diera lugar á las calamidades nunca bastante deploradas que fueron harto dolorosamente desastrosas para las provincias, iglesias, prelados, clero y órdenes religiosas de aquella nacion, y para sus intereses y bienes, con notabilísimo detrimento de la religión y de las almas" (BEOCLC, sábado 11 de junio de 1853, nº 2, p. 24).

47. Ha trabajado sobre ello y en relación con estas cuestiones de la prensa católica José Domínguez León en su texto "Iglesia y política en Andalucía a finales del siglo XIX. El adoctrinamiento a través de la prensa católica sevillana", en Trocadero: revista de historia moderna y contemporánea, n 5, 1993, pp. 149-172.

48. BEOCLC, sábado 11 de junio de $1853, n^{\circ} 2$, p. 24 . Defendían igualmente a continuación el restablecimiento de los bienes del clero que todavía no se habían vendido, aunque alguno de ellos, reconocía, se encontraba ya en un estado deplorable. Fundamentalmente a lo largo de los primeros años de este periódico se reflejó el deseo de la Iglesia de regularizar su posición en el país y sus relaciones con la corona. Defendían igualmente a continuación el restablecimiento de los bienes del clero que todavía no se habían vendido, aunque alguno de ellos, reconocía, se encontraba ya en un estado deplorable.

49. BEOCLC, sábado 3 de diciembre de 1853, n² 27, p. 214. 
tos de la fe y de confiar en la obra de Dios podrían llegar a alcanzar la felicidad y la fortuna, evitando así posibles males e infortunios ${ }^{50}$.

Los ilustrados, impíos o liberales de la primera mitad del siglo XIX provocaban, según el periódico, un entendimiento ofuscado en todos los seguidores de aquel movimiento, en todos aquellos que caían en "los vapores del error" La Iglesia debía dedicarse a predicar la fe, sus valores y la omnipresencia de Dios como salvador. Era el único camino a seguir para hacer frente al pensamiento liberal. Y así, desde la prensa de orientación católica se hacía un llamamiento a la sociedad: "Los padres de familia deben esmerarse en que la educación de sus hijos se base sobre los sólidos y salvadores principios de la fe. ¡Ay de ellos y de sus hijos si miran con indiferencia tan sagrado deber! Jamás deben permitirles la lectura de esas novelas inmorales que corrompen los corazones más rectos" ${ }^{\prime 52}$.

Desde La Rioja Católica también se clamó una lucha activa contra la impiedad y la irreligión. De ahí su posicionamiento contrario a la política liberal y la revolución:

“Porque la Religión tiene una vida propia, intrínseca e independiente de la política, no necesitando de ésta para nada; y los partidos han necesitado muchas veces, y necesitan todavía del nombre de la Religión para cubrir sus miras ambiciosas con un manto tan augusto. ¿Qué ha ido ganando la Religión con servir de escudo y de arma de combate en nuestras luchas intestinas? ¿Qué beneficio ha reportado de los partidos moderados que echaron mano de ella para alcanzar ventaja sobre sus adversarios los progresistas liberales?"53.

Por su parte, El Escudo Católico justificaba y defendía el uso de la prensa por parte de la Iglesia en su propio beneficio. Entendía que el clero se defiende de los ataques que recibe del liberalismo a través de las páginas de sus publicaciones y de los sermones al pueblo. "Cuando el clero ha visto hollado el Concordato, cuando el clero ha visto atacada por sus cimientos la estabilidad de la sociedad, cuando ha oído la apología de la libertad de cultos, cuando ha visto atacado lo más sagrado de la Religión", se ve obligado a defenderse ${ }^{54}$.

Esta reacción eclesiástica se plasmó de manera concreta en la redacción de numerosas noticias que instaban a los católicos a formar un verdadero

50. Esta referencia concreta proviene de El Escudo Católico, miércoles 15 de abril de 1857, $\mathrm{n}^{\circ} 7$, p. 196. Sin embargo, hay ejemplos similares a lo largo de toda la publicación con lenguaje y expresiones similares.

51. El Escudo Católico, jueves 15 de enero de 1857, año l, nº 1, p. 25.

52. El Escudo Católico, jueves 30 de abril de 1857, año I, nº 8, p. 235.

53. La Rioja Católica, 4 de febrero de 1893, año II, nº 5, pp. 1-2. El artículo que comprende estas expresiones lleva por título "Todo por el catolicismo y por España: nada por la política".

54. El Escudo Católico, domingo 15 de marzo de 1857, n 5, pp. 140-141. 
ejército contra los impíos liberales. Según La Rioja Católica debía ser un ejército que combatiera, desde las líneas de la fe, toda manifestación opuesta a ella bajo la consigna: “idelante los soldados de Cristo!”. Debía lucharse contra el liberalismo porque era "peste perniciosísima" y estaba "entronizado en todas partes" ${ }^{\prime \prime 5}$.

\subsection{Condena al liberalismo}

Como parte de este apartado podremos encontrar una condena manifiesta al liberalismo pero también, asociados directamente con éste, al racionalismo, sectarismo y protestantismo ${ }^{56}$. Fue sin lugar a duda una constante en la doctrina católica del momento a través de las páginas de todo el periodismo eclesiástico que se produjo en la segunda mitad del ochocientos ${ }^{57}$. Los contemporáneos de esta realidad creyeron que "contra la unidad de la fe, suele la política oponer la indiferencia entre todas las religiones, y la libertad de todos los cultos". Y junto a ello, "contra la caridad activa y consoladora de los cristianos, suele oponer la filantropía helada e infecunda de filosofastros sin alma"58.

De entre todos los caminos que los infieles podían seguir para atacar el cristianismo, el clero riojano iba a destacar uno por encima del resto: el liberalismo. Desde las páginas de La Rioja Católica se decía de esta tendencia política que era:

“El mismo liberalismo que en España arrojó a Dios de los templos para bailar el cancán en sus altares; en Francia fusiló a un Arzobispo después de haber asesinado a otros dos; y expulsó todas las Ordenes religiosas, y arrancó a las Hermanas de la Caridad de la cabecera de los enfermos, y quitó el Crucifijo de los hospitales, y prohibió enseñar a los niños la doctrina cristiana, y llenó las

55. Todo en La Rioja Católica, 31 de marzo de 1892, año II, nº 13, p. 5.

56. Por este motivo, en gran número de ocasiones a lo largo de las páginas de la prensa católica riojana se identificó a la masonería, basada en la hipocresía y egoísmo, con el protestantismo.

57. El adoctrinamiento que se llevaba a cabo desde la prensa eclesiástica en la sociedad del momento fue una realidad que compartió vía de difusión con otras obras contemporáneas. Es el caso de algunos textos entre los que podrían citarse el de J. Rodrigo de la Cerda, Compendio de la doctrina cristiana, Badajoz, Tip. y Enc. de Uceda Hnos., 1888, $7^{\mathrm{a}}$ ed, el de M. Encinas y del Soto, Breve exposición de la doctrina cristiana. Con arreglo al programa de esta asignatura y a la última reforma de la $2^{a}$ enseñanza, Valencia, Lib. de los sucesores de Badal, 1904, o el de J. Gou Sola, Lecciones razonadas de Religión y moral, antídoto contra los principales errores religiosos, antiguos y modernos, que ofrece a la juventud española el presbítero D..., Gerona, Imp. y Lib. de Paciano Torres, 1899.

58. La entrada en el mundo o guía práctica de la juventud cristiana, Madrid, Ad. Apostolado de la Prensa, 1898, pp. 201-202. Citado en José Domínguez León en su texto "Iglesia y política en Andalucía...", op. cit., p. 159. 
universidades, sin respetar el catolicismo, de libros de texto contrarios a la Religión y de textos vivos enemigos de ella y demás basura liberal" ${ }^{\prime 2}$.

Como puede entenderse a través de estas duras afirmaciones, la oposición al liberalismo viene de la mano del rechazo de éste por la predominancia del catolicismo en todos los ámbitos de la vida política. Las circunstancias que se vivían en España, y en general en la sociedad del momento, exigían ese esfuerzo máximo por parte de los cristianos para remediar los males que les aquejaban.

Citas literales de El Escudo Católico hacen hincapié en estas mismas ideas. Eran muchos los caminos que podían seguirse en aquella centuria hacia el olvido de Dios y de la Iglesia. Entre ellos destacaban el socialismo, la impiedad, la práctica de rituales en el seno de las sociedades secretas, el jacobinismo y, por encima de todos ellos, el liberalismo. Se criticaba a filósofos impíos, ateos, sociedades secretas y herejías, pero sobre todo a los liberales.

Desde los años 70 hasta final de siglo se produjo un completo rechazo a las expresiones políticas liberales y socialistas. No se trató de un movimiento meramente local o provincial, sino que respondió a una tendencia generalizada en España y en el resto de Europa. Se seguía en aquél el adoctrinamiento y doctrina pontificia. Se entendía que la Iglesia estaba siendo "fieramente combatida en sus doctrinas, en su autoridad, en su misión providencial en el mundo; la civil sociedad, arrancados de raíz los primeros fundamentos de todo orden". Se encontraba "minada por intestinas y profundas discordias y por obra de personas malvadas y audaces está amenazada de total ruina" ${ }^{\prime 60}$.

Tanto el liberalismo como el socialismo eran un peligro manifiesto para los intereses de la Iglesia católica. Según ésta el segundo era consecuencia lógica del primero y ambos estaban íntimamente vinculados a la ideología revolucionaria. La masonería también era un mal que aquejaba a la sociedad y se relacionaba directamente con los dos anteriores. Contra la masonería existe en La Rioja Católica, por ejemplo, un importante corpus en el que se deja entrever claramente el componente crítico que la Iglesia descarga contra esta institución. Se opuso a ella y dio muestras del temor manifiesto a que esta secta triunfase en la sociedad del momento ${ }^{61}$. También La Ciencia Eclesiástica, en su edición de 1884, reiteró la oposición ante las sociedades secretas y el daño que éstas podían causar en la mente humana. En el caso de la francmasonería se tachaba a ésta de "malhadada institución"62 que conllevaba terribles consecuencias para el mundo; una tenebrosa sociedad y una secta perniciosa.

59. La Rioja Católica, 7 de abril de 1892, año II, no 14, pp. 1-2.

60. La Revista Católica, 11 de enero de 1880, artículo "Balance social de Europa".

61. Ver referencias en el trabajo al respecto de Rebeca Viguera Ruiz, "El miedo a la masonería...", op. cit.

62. La Ciencia Eclesiástica, 20 de agosto de 1884, año III, n 23, p. 362. 
Desde el Boletín Eclesiástico del Obispado de Calahorra se aseguraba estar viviendo "en un siglo que dobla la rodilla al ídolo del interés material con menoscabo de la moral", un siglo en el que se había olvidado a Dios y se había vuelto la vista a los placeres prácticos de la vida ${ }^{63}$. Para este Boletín tales circunstancias suponían un claro paganismo y manifestaciones peligrosas del protestantismo ${ }^{64}$.

\subsection{Libertad de imprenta e Iglesia: dos realidades enfrentadas}

Junto a la defensa de la religión católica y el ataque a los principios liberales, las publicaciones eclesiásticas riojanas dedican un apartado especial en sus páginas a la cuestión de la libertad de imprenta. Desde el Boletín Eclesiástico del Obispado de Calahorra y La Calzada, sus responsables afirmaban comprender bien:

"Lo que es la libertad de imprenta con arreglo a nuestra Constitución y á nuestras leyes ó decretos; pero aquella y estas ó estos reconocen la prerrogativa divina de los obispos en materias religiosas, y como consecuencia declaran, que al obispo ha de acudirse para la publicación de tales escritos. Asi mismo concebimos bien, que el gobierno tenga sus fiscales de imprenta; pero semejante institución ni deroga ni puede derogar un átomo de la divina potestad de los obispos, porque el fiscal humano no puede excluir al fiscal divino, ni sustituirlo ni reemplazarlo" ${ }^{\prime \prime 5}$.

Desde esta perspectiva, la libertad de pensamiento era una posibilidad, pero la ley debía remediar los daños que los delitos contra ella pudieran ocasionar. El anunciado Boletín ofrecía su opinión al respecto a comienzos de los años 50 del ochocientos, y unos años más tarde El Escudo Católico ofrecería su propia visión de la necesidad de la censura previa para algunas publicaciones, o leyes represivas para otras ${ }^{66}$.

63. BEOCLC, sábado 22 de octubre de 1853, n 21, p. 169.

64. Continuaba referenciando en este punto alguna de las blasfemias más claras de estos movimientos contra la Iglesia. Una de ellas era la igualdad de los pecados. Afirmaba el periódico "Según los mismos sectarios, todas nuestras buenas obras son pecados: ¡oh impío monstruoso absurdo! Como pueden ser pecados siendo buenas obras? ¿Puede acaso ser bueno el pecado? Y según lo expuesto en la consideración antecedente, todos los pecados en la opinión de ellos son iguales: con que, todas nuestras buenas obras serán pecados iguales a los demás pecados ó malas obras; y asi, el orar á Dios será tan gran pecado como el blasfemar contra Dios... ¿Podrá darse cosa mas repugnante á la razon?". Vide en BEOCLC, sábado 24 de diciembre de 1853, nº 30, p. 242.

65. Todas estas alusiones y referencias en BEOCLC, sábado 22 de octubre de 1853, n²1, pp. $170-172$.

66. Ideas resumidas de las reflexiones que figuran en El Escudo Católico, lunes 15 de junio de $1857, \mathrm{n}^{\circ} 11$, pp. 330-331. 
Tanto esos dos periódicos como La Ciencia Eclesiástica y La Rioja Católica defendieron los intereses de los buenos periodistas ${ }^{67}$. Las obras de religión únicamente debían someterse a la revisión de los Obispos, que eran quienes actuarían como tribunal eclesiástico para velar por los intereses de la Iglesia. Se limitaba igualmente la cantidad de periodistas que podían ejercer considerando que no todos podían escribir e imprimir sus pensamientos en hojas sueltas, sino sólo aquéllos que reunieran las cualidades prescritas por la ley: una edad mínima de veinticinco años, y haber aprobado cuatro años de estudios mayores en cualquier facultad ${ }^{68}$.

Artículos de estas características en oposición a la libertad de imprenta se justifican desde estas publicaciones por ser una de las cuestiones que más preocupaban a la sociedad. El Escudo católico afirmó a este respecto que de "entre las cuestiones que desde la revolución de 1789 vienen agitándose en la civilizada Europa, ninguna tan trascendental como la libertad de imprenta; ninguna ha dado lugar á tantas discusiones, y de ninguna se han ocupado tanto los hombres públicos" ${ }^{\prime \prime 9}$.

Gracias a aquélla se consiguió un alto grado de libertad de expresión en la España decimonónica. Sin embargo, la Iglesia, por cuanto suponía un riesgo en su dominio ideológico y religioso sobre el pueblo, encontró siempre en ella un motivo de ataque al sistema político liberal de la segunda mitad del siglo XIX.

\section{Conclusiones}

Consciente del poder de la prensa, la Iglesia se lanzó desde mediados del siglo XIX a contrarrestar "Ios malos efectos de la impía libertad de cultos y de la indiferencia religiosa"70. Lo haría a través de publicaciones que tenían como objetivo complementario la educación del pueblo. Concebía aquélla la enseñanza como el mejor medio para salir de la lamentable situación que atravesaba la sociedad española. Muchas de las publicaciones católicas tuvieron como objetivo llegar al público en general, al lector medio, a través de un lenguaje sencillo, variedad de temas, y el establecimiento de un código de conducta de un buen cristiano. Fue sin duda el caso de la analizada prensa católica riojana.

67. La Rioja Católica, 1893, año III, nº 25, p. 319.

68. Todo ello porque "se necesita más ciencia, más experiencia, más juicio, más sensatez que lo que comúnmente acompaña a la juventud, que más fácilmente se ilusiona con bellas teorías, y fácilmente se engaña con algunos conocimientos superficiales". Consecuencia de ello era la invalidez para escribir de todos aquellos que fuesen conocidos por sus principios anticatólicos o atacasen con violencia los principios de la civilización cristiana. Vide El Escudo Católico, lunes 15 de junio de 1857, n 11, p. 333.

69. El Escudo Católico, lunes 15 de junio de 1857, nº 11, p. 329.

70. Idea contenida en La Enseñanza Católica, n 1, 7 de enero de 1872, pp. 1-2. 
No obstante, pese a los reiterados intentos de la Iglesia, la gran mayoría de la población, incluyendo muchos católicos practicantes, iban a seguir decantándose por la lectura de la prensa liberal. La prensa católica compartía con esta última a finales del siglo XIX algunos rasgos comunes como eran la venta por suscripción, una vida corta y su pronta desaparición.

El contenido ideológico y estructural de los periódicos analizados no es exclusivo de la producción periodística riojana, sino que se enmarca dentro del marco legal de imprenta establecido en España a partir de la segunda mitad del ochocientos. Del mismo modo tiene reflejo en ellos la generalizada reacción eclesiástica antiliberal de la Iglesia de dicho siglo. Pese a la diferente naturaleza estructural de cada una de las cuatro publicaciones señaladas, mantienen una misma ideológica en torno en tres principios: un constante ataque hacia el sistema liberal, sus partidarios y sus actividades, una clara oposición frente a todo lo que vilipendiase los principios fundamentales de la doctrina de la Iglesia Católica, y una negación rotunda de la política española del momento ${ }^{71}$.

A pesar de sus divergencias, suponen un claro ejemplo de la reacción común de la jerarquía eclesiástica que puso en marcha en España un importante proceso de edición de publicaciones periódicas destinadas a defender la fe de los cristianos y atacar la impiedad que proliferaba en las sociedades contemporáneas. Un medio por el que se podía llevar a cabo una justificación de la fe, del Catolicismo y del poder de la Iglesia como mediadora entre Dios y los hombres.

Ante la persecución a la que la Iglesia se veía sometida y ante la pérdida de valores cristianos de la sociedad, con la consiguiente reducción de la influencia de la Iglesia en el Estado, esta prensa católica local era una de las vías más seguras para llamar la atención del pueblo sobre los males de la época.

71. Reflexión ya sostenida en Rebeca Viguera Ruiz, "El miedo a la masonería...", op. cit., p. 124. 